Cite this: Chem. Commun., 2014. 50, 9469

Received 16th June 2014,

Accepted 4th July 2014

DOI: $10.1039 / \mathrm{c} 4 \mathrm{cc} 04555 f$

www.rsc.org/chemcomm

\title{
Facile regiospecific synthesis of 2,3-disubstituted indoles from isatins $\dagger$
}

\author{
Xiaowei Dou, Weijun Yao, Shan Wen and Yixin Lu*
}

\begin{abstract}
A facile regiospecific synthesis of 2,3-disubstituted indoles from isatins has been developed. Nucleophilic addition of Grignard reagents to commercially available isatins, followed by reduction with borane, afforded an array of structurally diverse 2,3-disubstituted indoles in moderate to good yields. The method described herein represents a novel and very simple approach to synthesize various 2,3-disubstituted indoles, extremely important structural motifs in the pharmaceutical industry and medicinal chemistry.
\end{abstract}

Indole represents one of the most important structural units of natural products and pharmaceutical agents, ${ }^{1}$ and continuous efforts have been devoted to the efficient synthesis of indole structures over the past century. ${ }^{2}$ Fisher indole synthesis, although discovered more than 100 years ago, still remains one of the most widely used methods. ${ }^{3}$ Many transition metalbased approaches have emerged over the past few decades, including Larock aniline-alkyne cyclizations, ${ }^{4} \mathrm{C}-\mathrm{H}$ activation strategies, ${ }^{5}$ and cross-dehydrogenative coupling methods, ${ }^{6}$ among others (Scheme 1). Despite the aforementioned impressive progress, straightforward and efficient methods without employing a transition metal are still highly desired. Given the importance of 2,3-disubstituted indoles in biological sciences and medicinal chemistry (Fig. 1), ${ }^{7}$ we set out to design an efficient method to access such structural motifs. The vast majority of known methods rely on the annulation of a five-membered ring to an existing benzene ring for the construction of the indole core, and synthesis of specific precursors containing the right functionalities can pose huge synthetic problems. Moreover, formation of mixed regioisomers at the 2-and 3-positions is often problematic in the above approaches. In our design, we set the following criteria for starting materials to ensure an efficient indole synthesis: (1) ready availability, (2) the existing fused ring structures, (3) latent indole

Department of Chemistry and Medicinal Chemistry Program, Life Sciences Institute, National University of Singapore, 3 Science Drive 3, Republic of Singapore 117543. E-mail: chmlyx@nus.edu.sg

$\dagger$ Electronic supplementary information (ESI) available. See DOI: 10.1039/ c4cc04555f
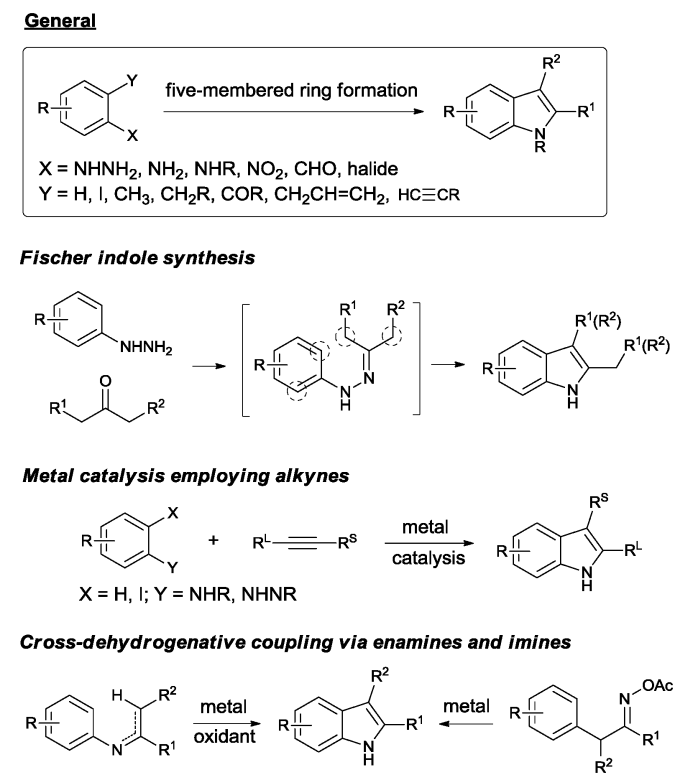

Scheme 1 Common methods for indole synthesis.
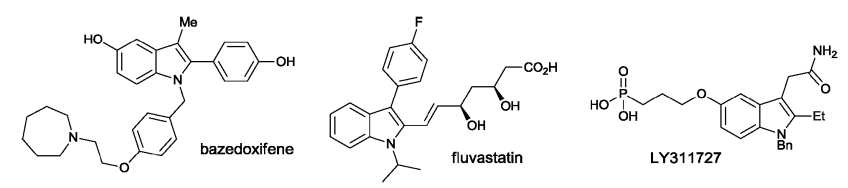

Fig. 1 Selected bioactive compounds containing a 2,3-disubstituted indole moiety.

precursors, and (4) easy functionalization to allow access to different 2,3-substituted indoles. Commercially available isatins seem to be excellent candidates fulfilling all the above requirements. Nucleophilic additions to the carbonyl groups at 2- and 3-positions could yield 2,3-disubstituted intermediates. Moreover, the carbonyl groups at 2- and 3-positions of isatins have different electrophilic properties, and thus careful differentiation of these groups is expected to make selective functionalizations possible, thus 


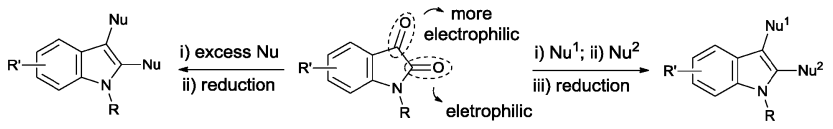

Scheme 2 Synthesis of 2,3-disubstituted indoles from isatins.

Table 1 Investigating the synthesis of 2,3-disubstituted indoles from isatins ${ }^{a}$

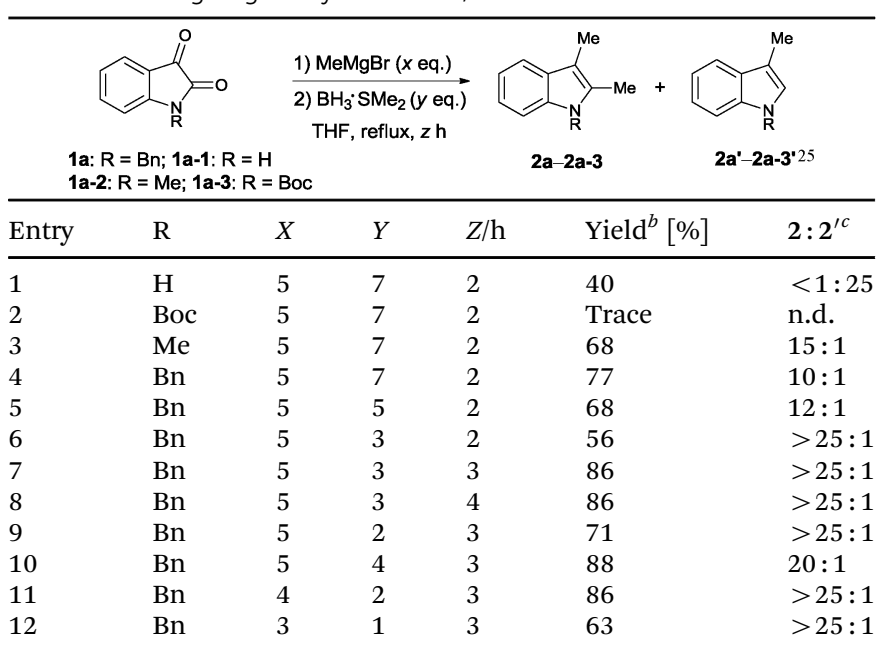

${ }^{a}$ Reactions were performed with $\mathbf{1 a}(0.2 \mathrm{mmol}), \operatorname{MeMgBr}(x$ eq., $3.0 \mathrm{M}$ in $\mathrm{Et}_{2} \mathrm{O}$ ), $\mathrm{BH}_{3}-\mathrm{SMe}_{2}$ ( $y$ equiv., $2.0 \mathrm{M}$ in THF) in THF $(1.0 \mathrm{~mL}), 0{ }^{\circ} \mathrm{C}$ to reflux. ${ }^{b}$ Combined isolated yield of 2 and $2^{\prime}$. ${ }^{c}$ Determined by ${ }^{1} \mathrm{H}$ NMR analysis.

introducing different substituents at 2- and 3-positions. Finally, using a suitable reduction protocol, ${ }^{8}$ various 2,3 -disubstituted indoles can be readily created (Scheme 2).

We first tested the feasibility of forming indoles from isatins, installing the same substituent at the 2- and 3-positions. The methyl group was introduced via a methyl Grignard reagent, and subsequent reduction with borane yielded the indole products (Table 1). We initially employed 5 equivalents of the Grignard reagent as well as a large excess of borane (7 eq.) to ensure high conversion of the reaction. When unprotected isatin (1a) was used, only a 3-monosubstituted indole product (2a-1') was obtained in low yield, (entry 1). When Boc-protected isatin (3a) was used, the desired indole product was virtually not formed (entry 2). Switching the N-protection to an alkyl group proved to be effective, and the desired 2,3-disubstituted indole was obtained in high yield when $N$-methyl or $N$-benzyl isatin was used for the reaction (entries 3 and 4). However, it was observed that 3-monosubstituted indole was also formed during the reaction, which could not be easily separated from the desired disubstituted product via chromatographic separation. We reasoned that varying the molar equivalence of the Grignard reagent and borane might be the key to solving this problem. Therefore, further optimizations were carried out. When the amount of borane was reduced to 3 equivalents, the 2,3-disubstituted indole 2a was obtained as the sole product in moderate yield (entry 6). The chemical yield was easily improved to $86 \%$ with slightly increased reaction time (entries 7 and 8). Further experimentations revealed the best reaction conditions; in the presence of 4 equivalents of the Grignard reagent and
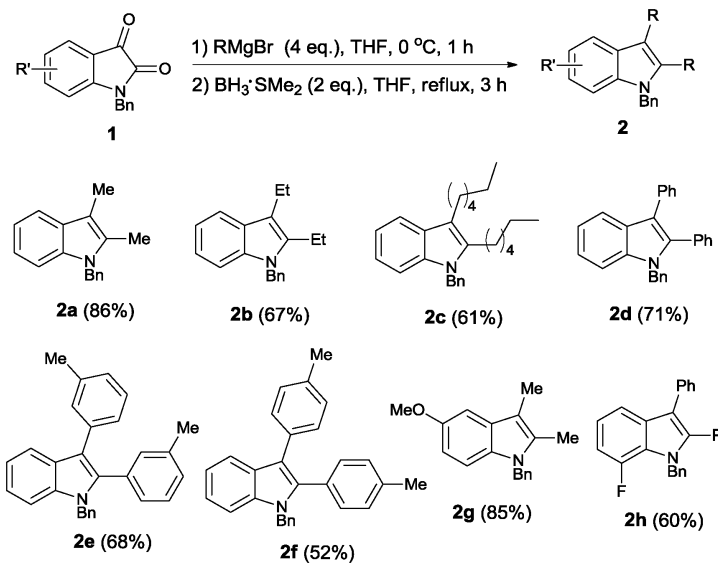

2b (67\%)

2c (61\%)

2d $(71 \%)$

Scheme 3 Substrate scope for synthesis of symmetric 2,3-disubstitutedindoles.

2 equivalents of borane, the desired 2,3-disubstituted indoles were formed in high yields (entry 11). ${ }^{9}$

By utilizing the above optimal reaction conditions, we prepared a number of symmetric 2,3-disubstituted indoles from isatins (Scheme 3). Various alkyl and aryl substituents were easily installed at the 2- and 3-positions with employment of different Grignard reagents ${ }^{10}$ (2a-2f). Furthermore, indole core structures could also be varied if different isatins were utilized as starting materials ( $\mathbf{2} \mathbf{g}$ and $\mathbf{2 h}$ ).

Our next goal was to regiospecifically synthesize 2,3-disubstituted indoles bearing different substituents. This is a formidable synthetic task, and previous literature efforts only met with limited success. ${ }^{11}$ We reasoned that this challenging regioselectivity issue may be easily addressed via stepwise functionalization of the indole precursor, taking advantage of the difference in electrophilicity of the 2- and 3-carbonyl groups of isatins. Treatment of $N$-benzyl isatins with the Grignard reagent at low temperature yielded 3-hydroxy-3-substituted oxindole substrates $3{ }^{12}$ which were then subjected to the second functionalization at the 2-carbonyl position. The reaction was conducted in the presence of 4 equivalents of the Grignard reagent and 2 equivalents of borane, and the results are summarized in Scheme 4. 2,3-Disubstituted indoles with different substitution patterns were easily prepared, including: 2-alkyl-3-alkyl (4a-4d), 2-aryl-3-alkyl (4e-4h), 2-alkyl-3-aryl (4i-4l), and 2-aryl-3-aryl (4m-4p) substituents. Moreover, different indole cores could be obtained if different isatins were utilized as the starting materials (4q-4t). All the products were readily prepared, within a few hours, in moderate to good chemical yields. It is noteworthy that our method allowed convenient preparation of 2,3-disubstituted indoles in a regiospecific manner, even though the substituents may have great similarity both sterically and electronically. For instance, 2-methyl-3-ethyl-indole $4 \mathbf{a}$ and 2-ethyl-3-methyl-indole $\mathbf{4 b}$ were prepared in high yields, both as a pure regioisomer, as opposed to the formation of mixed isomers reported in the literature. ${ }^{13}$ The 2,3-disubstituted indoles could also be synthesized via a one-pot protocol. Isatin 1a was treated with different Grignard reagents in a stepwise fashion, the phenyl group was first 


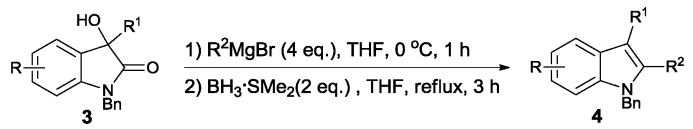<smiles>CCc1c([N+](=O)[O-])[nH]c2ccccc12</smiles><smiles>CCc1[nH]c2ccccc2c1[N+](=O)[O-]</smiles><smiles>Cc1[nH]c2ccccc2c1C(C)(C)C</smiles><smiles>C[14C]1=C(Br)c2ccccc2[N]1</smiles>

$4 a(87 \%)$

4b $(79 \%)$

4c $(65 \%)$
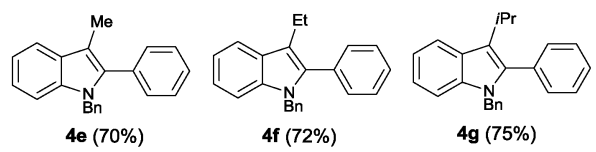

4d (63\%)<smiles>Cc1[nH]c2ccccc2c1-c1ccccc1</smiles><smiles>CCc1[nH]c2ccccc2c1-c1ccccc1</smiles>
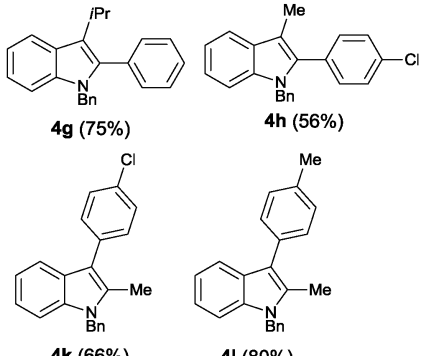

4h (56\%)
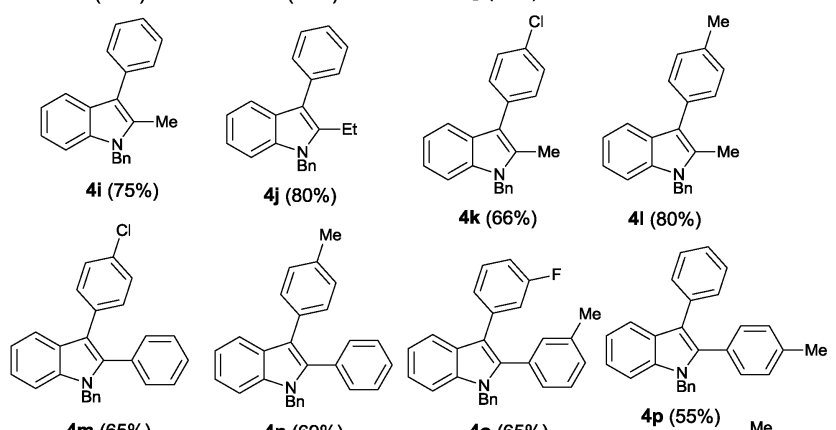<smiles>CCc1c([N+](=O)[O-])[nH]c2ccc(OC)cc12</smiles>

4n $(69 \%)$
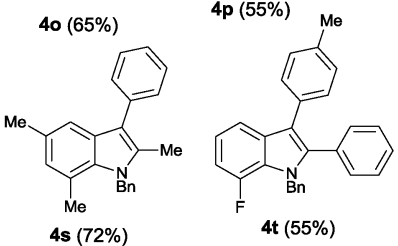

Scheme 4 Regiospecific synthesis of 2,3-disubstituted-indoles bearing different substituents.

introduced into the 3-position, followed by 2-carbonyl functionalization with another Grignard reagent. Finally, the desired product was obtained upon borane reduction (eqn (1)).

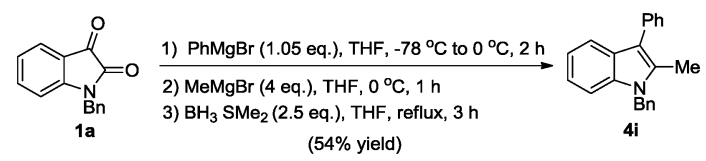

The synthetic value of our method was demonstrated by preparing LY311727, the first potent and selective $\mathrm{S}-\mathrm{PLA}_{2}$ inhibitor. $^{7 b} 3$-Hydroxy oxindole substrate 6 was easily derived from isatin 5 (see the ESI $\dagger$ for details). Treatment of 6 with ethylmagnesium bromide led to the formation of indoline 7 , instead of the corresponding indole intermediate. Indole 8 was obtained via a mesylation-elimination reaction. ${ }^{14}$ Removal of the silyl protection afforded the key intermediate $\mathbf{9}$, which can

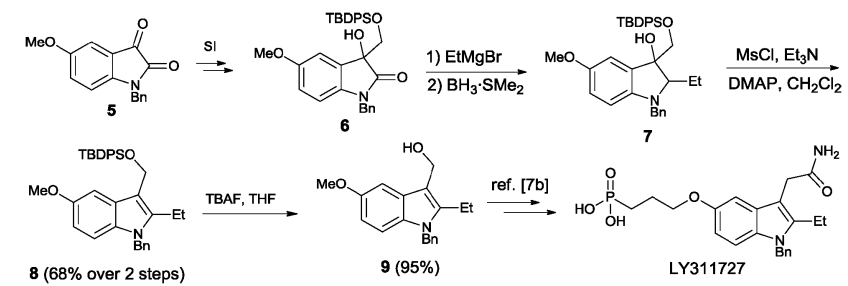

Scheme 5 A formal synthesis of LY311727.

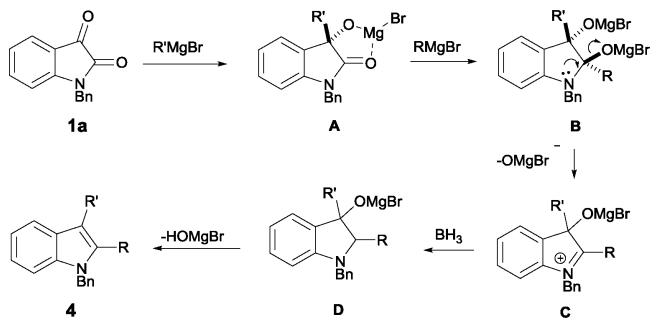

Scheme 6 Proposed reaction pathway.

be converted into LY311727 using the procedures described in the literature (Scheme 5).

Unprotected indole products could be easily obtained after the $N$-debenzylation reaction. The benzyl group of 40 could be readily removed by treating it with potassium tert-butoxide and oxygen in DMSO/THF at room temperature, and the corresponding unprotected indole $\mathbf{1 0}$ was obtained in high yield (eqn (2)). ${ }^{15}$

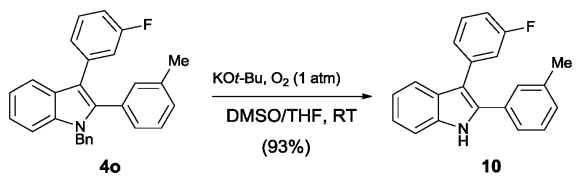

A plausible reaction pathway is illustrated in Scheme 6 . Treatment of isatin 1a with a Grignard reagent yields intermediate A. Excess Grignard reagent leads to the formation of intermediate $\mathbf{B}$. Upon the elimination of $\mathrm{OMgBr}^{-}$, iminium intermediate $\mathbf{C}$ is generated, which is further reduced to indoline intermediate $\mathbf{D}$. The final indole product $\mathbf{4}$ is then generated upon subsequent elimination of $\mathrm{Mg}(\mathrm{OH}) \mathrm{Br}$.

In summary, we have successfully developed a novel method for regiospecific preparation of 2,3-disubstituted indoles. Our method makes use of commercially available isatins as starting materials, and employs readily available Grignard reagents as nucleophilic partners and borane as a convenient reducing agent. Stepwise functionalization of the 2- and 3-carbonyl groups of isatins is the key to the introduction of different substituents regiospecifically at the 2- and 3-positions of the indole products. Extension of the approach described here to the synthesis of other important heterocyclic compounds is ongoing in our laboratory.

\section{Notes and references}

1 (a) M. Inman and C. J. Moody, Chem. Sci., 2013, 4, 29; (b) A. J. Kochanowska-Karamyan, Chem. Rev., 2010, 110, 4489; (c) T. Kawasaki and K. Higuchi, Nat. Prod. Rep., 2007, 24, 843; (d) T. Kawasaki and K. Higuchi, Nat. Prod. Rep., 2005, 22, 761; (e) M. Somei and F. Yamada, Nat. Prod. Rep., 2005, 22, 73; $(f)$ M. Somei and F. Yamada, Nat. Prod. Rep., 2004, 21, 278; $(g)$ R. J. Sundberg, Indoles, Academic Press, San Diego, 1996.

2 For recent reviews on indole synthesis, see: (a) M. Shiri, Chem. Rev., 2012, 112, 3508; (b) S. Cacchi and G. Fabrizi, Chem. Rev., 2011, 111, PR215; (c) D. F. Taber and P. K. Tirunahari, Tetrahedron, 2011, 67, 7195; (d) R. Vicente, Org. Biomol. Chem., 2011, 9, 6469; (e) K. Krüger, A. Tillack and M. Beller, Adv. Synth. Catal., 2008, 350, 2153; $(f)$ G. R. Humphrey and J. T. Kuethe, Chem. Rev., 2006, 106, 2875; $(g)$ S. Cacchi and G. Fabrizi, Chem. Rev., 2005, 105, 2873; 
(h) G. Bartoli, R. Dalpozzo and M. Mardi, Chem. Soc. Rev., 2014, 43, 4728.

3 For reviews on the Fischer indole synthesis, see: (a) D. L. Hughes, Org. Prep. Proced. Int., 1993, 25, 607; (b) B. Robinson, The Fischer Indole Synthesis Wiley-Interscience, New York, 1982; (c) B. Robinson, Chem. Rev., 1969, 69, 227; (d) B. Robinson, Chem. Rev., 1963, 63, 373. For selected recent modifications, see: $(e)$ M. Inman, A. Carbone and C. J. Moody, J. Org. Chem., 2012, 77, 1217; $(f)$ M. Inman and C. J. Moody, Chem. Commun., 2011, 47, 788; $(g)$ B. A. Haag, Z.-G. Zhang, J.-S. Li and P. Knochel, Angew. Chem., Int. Ed., 2010, 49, 9513; (h) K. Alex, A. Tillack, N. Schwarz and M. Beller, Angew. Chem., Int. Ed., 2008, 47, 2304; (i) C. Cao, Y. Shi and A. L. Odom, Org. Lett., 2002, 4, 2853; $(j)$ S. Wagaw, B. H. Yang and S. L. Buchwald, J. Am. Chem. Soc., 1998, 120, 6621.

4 (a) G. Zeni and R. C. Larock, Chem. Rev., 2006, 106, 4644; (b) R. C. Larock and E. K. Yum, J. Am. Chem. Soc., 1991, 113, 6689; (c) R. C. Larock, E. K. Yum and M. D. Refvik, J. Org. Chem., 1998, 63, 7652.

5 For representative examples, see: $(a)$ D. Zhao, Z. Shi and F. Glorius, Angew. Chem., Int. Ed., 2013, 52, 12426; (b) C. Wang, H. Sun, Y. Fang and Y. Huang, Angew. Chem., Int. Ed., 2013, 52, 5795; (c) B. Liu, C. Song, C. Sun, S. Zhou and J. Zhu, J. Am. Chem. Soc., 2013, 135, 16625; (d) C. Wang and Y. Huang, Org. Lett., 2013, 15, 5294; (e) M. P. Huestis, L. Chan, D. R. Stuart and K. Fagnou, Angew. Chem., Int. Ed., 2011, 50, 1338; $(f)$ D. R. Stuart, P. Alsabeh, M. Kuhn and K. Fagnou, J. Am. Chem. Soc., 2010, 132, 18326; (g) D. R. Stuart, M. Bertrand-Laperle, K. M. N. Burgess and K. Fagnou, J. Am. Chem. Soc., 2008, 130, 16474. For palladium catalyzed reactions, see: (h) S. P. Breazzano, Y. B. Poudel and D. L. Boger, J. Am. Chem. Soc., 2013, 135, 1600; (i) Z. Shi, C. Zhang, S. Li, D. Pan, S. Ding, Y. Cui and N. Jiao, Angew. Chem., Int. Ed., 2009, 48, 4572.

6 For a highlight, see: (a) Z. Shi and F. Glorius, Angew. Chem., Int. Ed., 2012, 51, 9220. For palladium catalyzed reactions, see: $(b)$ Y. Wei, I. Deb and N. Yoshikai, J. Am. Chem. Soc., 2012, 134, 9098; (c) T. Nanjo, C. Tsukano and Y. Takemoto, Org. Lett., 2012, 14, 4270; (d) J. J. Neumann, S. Rakshit, T. Dröge, S. Würtz and F. Glorius, Chem. - Eur. J., 2011, 17, 7298; (e) Y. Tan and J. F. Hartwig, J. Am. Chem. Soc., 2010, 132, 3676; $(f)$ S. Würtz, S. Rakshit, J. J. Neumann, T. Dröge and F. Glorius, Angew. Chem., Int. $E d$., 2008, 47, 7230. For other metal catalyzed reactions, see: $(g)$ A. Gogoi, S. Guin, S. K. Rout and B. K. Patel, Org. Lett., 2013, 15, 1802; $(h)$ B. Lu, Y. Luo, L. Liu, L. Ye, Y. Wang and L. Zhang, Angew. Chem., Int. Ed., 2011, 50, 8358; (i) Z.-H. Guan, Z.-Y. Yan, Z.-H. Ren, X.-Y. Liu and Y.-M. Liang, Chem. Commun., 2010, 46, 2823; (j) R. Bernini, G. Fabrizi, A. Sferrazza and S. Cacchi, Angew. Chem., Int. Ed., 2009, 48, 8078; (k) M. Shen, B. E. Leslie and T. G. Driver, Angew. Chem., Int. Ed., 2008, 47, 5056. For a metal-free version, see: (l) W. Yu, Y. Du and K. Zhao, Org. Lett., 2009, 11, 2417.

7 (a) K. Alex, N. Schwarz, V. Khedkar, I. A. Sayyed, A. Tillack, D. Michalik, J. Holenz, J. L. Diaz and M. Beller, Org. Biomol. Chem., 2008, 11, 2417; (b) J. M. Paolak, V. V. Khau, D. R. Hutchison and M. J. Martinelli, J. Org. Chem., 1996, 61, 9055; (c) A. Arcadi, S. Cacchi, V. Carnicelli and F. Marinelli, Tetrahedron, 1994, 50, 437. Also see ref. $1 a, 2 b, e$.

8 For reduction of oxindole to indole, see: $(a) \mathrm{W}$. Wierenga, J. Griffin and M. A. Warpehoski, Tetrahedron Lett., 1983, 24, 2437; (b) S. J. Garden, R. B. da Silva and A. C. Pinto, Tetrahedron, 2002, 58, 8399.

9 The first nucleophilic addition of a Grignard reagent to the 3-carbonyl group proceeds readily and quantitatively. The second nucleophilic addition of Grignard to the 2-carbonyl group is more difficult, due to lower electrophilicity of the amide function. In the presence of excess borane, reduction of the amide carbonyl competes with nucleophilic addition, accounting for the formation of 3-monosubstituted indoles.

10 When vinylmganesium bromide was used under the optimized reaction conditions, no desired product was observed.

11 Only a handful of examples have described the synthesis of asymmetric 2,3-disubstituted indoles, see: (a) B. Yao, Q. Wang and J. Zhu, Angew. Chem., Int. Ed., 2012, 51, 12311; (b) S. Cacchi, G. Fabrizi, A. Goggiamani, A. Perboni, A. Sferrazza and P. Staqbile, Org. Lett., 2010, 12, 3279; (c) B. Z. Lu, W. Zhao, H.-X. Wei, M. Dufour, V. Farina and C. H. Senanayake, Org. Lett., 2006, 8, 3271; (d) H. Tokuyama, T. Yamashita, M. T. Reding, Y. Kaburagi and T. Fukuyama, J. Am. Chem. Soc., 1999, 121, 3791; (e) T. Fukuyama, X. Chen and G. Peng, J. Am. Chem. Soc., 1994, 116, 3127; $(f)$ K.-Y. Ye, L.-X. Dai and S.-L. You, Chem. - Eur. J., 2014, 20, 3040. Also see some examples in ref. 5a,b,d,e.

12 For preparation of 3-hydroxy-3-substituted oxindole from isatins, see: B. M. Trost, J. Xie and J. D. Sieber, J. Am. Chem. Soc., 2011, 133, 20611, and the ESI $\dagger$ of this article.

13 A $3: 2$ mixture was obtained in Larock indole synthesis, see: R. C. Larock, E. K. Yum and M. D. Refvik, J. Org. Chem., 1998, 63, 7652.

14 Formation of the indole core via dehydration of an indoline intermediate did not occur spontaneously under standard reaction conditions, which may be due to the formation of a stable fivemembered intermediate resulting from coordination of magnesium with the two oxygen atoms at the 3-position.

15 A. A. Haddach, A. Kelleman and M. V. Deaton-Rewolinski, Tetrahedron Lett., 2003, 43, 399. 